\title{
Functional alleles of the flowering time regulator FRIGIDA in the Brassica oleracea genome
}

\author{
Judith A Irwin', Clare Lister', Eleni Soumpourou', Yanwen Zhang ${ }^{1}$, Elaine C Howell'2, Graham Teakle ${ }^{3}$ and \\ Caroline Dean ${ }^{1 *}$
}

\begin{abstract}
Background: Plants adopt different reproductive strategies as an adaptation to growth in a range of climates. In Arabidopsis thaliana FRIGIDA (FRI) confers a vernalization requirement and thus winter annual habit by increasing the expression of the MADS box transcriptional repressor FLOWERING LOCUS C (FLC). Variation at FRI plays a major role in $A$. thaliana life history strategy, as independent loss-of-function alleles that result in a rapid-cycling habit in different accessions, appear to have evolved many times. The aim of this study was to identify and characterize orthologues of FRI in Brassica oleracea.
\end{abstract}

Results: We describe the characterization of FRI from Brassica oleracea and identify the two B. oleracea FRI orthologues (Bo/C.FRI.a and Bo/C.FRI.b). These show extensive amino acid conservation in the central and C-terminal regions to FRI from other Brassicaceae, including $A$. thaliana, but have a diverged $\mathrm{N}$-terminus. The genes map to two of the three regions of $B$. oleracea chromosomes syntenic to part of $A$. thaliana chromosome 5 suggesting that one of the $F R I$ copies has been lost since the ancient triplication event that formed the B. oleracea genome. This genomic position is not syntenic with $F R I$ in $A$. thaliana and comparative analysis revealed a recombination event within the $A$. thaliana FRI promoter. This relocated $A$. thaliana FRI to chromosome 4, very close to the nucleolar organizer region, leaving a fragment of $F R I$ in the syntenic location on A. thaliana chromosome 5. Our data show this rearrangement occurred after the divergence from $A$. lyrata. We explored the allelic variation at Bo/C.FRI.a within cultivated B. oleracea germplasm and identified two major alleles, which appear equally functional both to each other and A. thaliana FRI, when expressed as fusions in A. thaliana.

Conclusions: We identify the two Brassica oleracea FRI genes, one of which we show through $A$. thaliana complementation experiments is functional, and show their genomic location is not syntenic with $A$. thaliana FRI due to an ancient recombination event. This has complicated previous association analyses of $F R /$ with variation in life history strategy in the Brassica genus.

Keywords: FRIGIDA, Flowering time, vernalization, synteny, Brassica oleracea, Arabidopsis thaliana

\section{Background}

The switch to reproductive development is a fundamental process in the plant life cycle. The molecular mechanisms underlying this developmental transition have been extensively studied in Arabidopsis thaliana. An integrated network of environmentally responsive genetic pathways converge on a common set of targets to quantitatively regulate the genes required to switch the apical

\footnotetext{
* Correspondence: caroline.dean@jic.ac.uk

'Department of Cell and Developmental Biology, John Innes Centre,

Norwich Research Park, Norwich NR4 7UH, UK Full list of author information is available at the end of the article
}

meristem from a vegetative to a floral state [1-3]. One important environmental cue is prolonged cold, which accelerates flowering in a process termed vernalization and aligns pollination and seed set with the favourable conditions of spring. Variation in requirement for vernalization exists in many plant species and this influences life history strategy with plants requiring vernalization adopting a perennial, biennial or winter annual habit in contrast to summer annuals, which flower in the first growing season. This is in contrast to other species that are more reliant on photoperiodic signals or endogenous cues e.g. rice [4]. The significant fitness consequences of
C Biomed Central 
flowering time variation, demonstrated in annual $[5,6]$ and perennial plants [7], have most likely contributed to the evolution of the extensive variability in flowering time control. Flowering also influences the pattern of growth throughout the seasons and affects many agronomic characters including the quantity and quality of crop production. This is particularly apparent in cultivated brassicas, where variation in the flowering process has been selected to produce a diverse array of economically important morphological forms.

A major determinant in the variation of vernalization requirement in $A$. thaliana is allelic variation at FRIGIDA $(F R I)$ [8-11]. FRI represses flowering by promoting the expression of the floral repressor FLOWERING LOCUS C $(F L C)[12,13]$. Vernalization acts antagonistically to FRI and accelerates flowering by down-regulating FLC. A number of rapid-cycling variants of $A$. thaliana that do not need vernalization were found to have arisen through loss of function of FRI, an evolutionary step that has occurred multiple times $[8,9,11,14]$. Parallel evolution through allelic variation at a common target has been found in other organisms [15]. It was therefore interesting to ask whether a similar evolutionary step has occurred in other plant species. Many other species do show variation in vernalization requirement and it is an important agronomic trait in many major crops. For example, in B. oleracea (horticultural brassicas) vernalization-requiring biennials are represented by cabbage and Brussels sprouts, with summer annual crops including some calabrese and cauliflower cultivars. Orthologues of FRI have been identified in A. lyrata [16], Capsella species [17] and the halophyte Thellungiella halophila [18] within the Brassicaceae, and more broadly in Medicago truncatula, Lotus japonicus, Vitis vinifera [19], Populus balsamifera [20] and Oryza sativa [21]. To date natural variation in vernalization requirement has been associated with FRI polymorphism in A. lyrata [8] and allelic variation in one orthologue in Brassica napus (BnaA.FRI.a) has been associated with flowering time variation [22].

We are interested in understanding the molecular basis of variation in flowering time and vernalization requirement in horticultural brassicas. Genetic information from A. thaliana can generally be applied to Brassica species because of their evolutionary relatedness. The Arabidopsis and Brassica genera are in the same family (Brassicaceae) with $B$. oleracea thought to have arisen from a triplication of an ancestral genome similar to that of Arabidopsis [23-26]. Genetic information on the control of flowering in Arabidopsis can be applied to Brassica species because of the colinearity of the Arabidopsis and Brassica genomes $[23,27,28]$. This has been used to infer candidate genes that might account for QTL underlying flowering time and other variation [22,29,30]; however, in some instances it can be misleading [31]. Here, we identify the two FRI genes in the B. oleracea genome and map their genomic locations. We also explored allelic variation at one of the FRI loci in cultivated $B$. oleracea germplasm. These new data will provide the necessary information to elucidate how general a role FRI plays in life history variation in the Brassicaceae.

\section{Results and discussion}

Two FRI genes are present in the Brassica oleracea genome

The BoFRI genes were isolated from the JBo BAC library of the B. oleracea Chinese kale genotype A12DHd [32] through hybridization with an $A$. thaliana FRI genomic clone. From seven positive BAC clones two that showed distinct FRI hybridization patterns (JBo72I23 and JBo88G16, Figure 1a, b) were selected for sub-cloning. Analysis of these confirmed they carried different Brassica paralogues designated BolC.FRI.a and BolC.FRI.b [33] and referred to hereafter as BoFRIa and BoFRIb [GenBank JN191450 and JN191449]. As in other species, BoFRIa and BoFRIb contain three exons encoding predicted open reading frames (ORFs) of 594 and 585 residues respectively (Figure 1c). BoFRIa contains two coiled-coil domains, typically involved in protein oligomerisation (as predicted by COILS http://www.ch.embnet.org/software/COILS_form.html[34]), very similar to the predicted structure of the A. thaliana FRI (AtFRI) $[8,35]$. In contrast, BoFRIb is predicted to contain only one coiled-coil domain in the $\mathrm{C}$-terminal region as was found to be the case for two of the four FRI identified in B. napus [22].

AtFRI is the original member of a family of seven proteins in $A$. thaliana which, apart from the two predicted coiled-coil domains, show no homology with any other proteins and whose function has yet to be determined. Recent analysis of the FRI protein family [19] identified a conserved core central domain. Outside of this domain significant variation is observed that allows the FRI family to be subdivided into five distinct groups. AtFRI and its orthologues in other species are defined by a conserved region of 37 amino acids in the $\mathrm{N}$-terminal region of the protein. The BoFRI proteins we describe here contain this conserved 37 amino acid region reinforcing the view they are FRI orthologues; however, the amino acids either side of this region show lower homology to AtFRI (Figure 1c). This region includes much of the first predicted coiledcoil in BoFRIa. Variations in this domain in BoFRIb result in the loss of a predicted coiled-coil, emphasising a possible functional significance for the amino acid polymorphisms in this region. A similar degree of divergence from AtFRI is found in the $\mathrm{N}$-terminal region of an orthologue of FRI isolated from the halophyte $T$. halophila and in four orthologues of FRI identified in B. napus [18,22]. By contrast, there is extensive amino acid conservation 
(a)

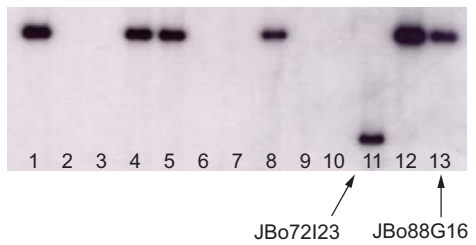

(b)

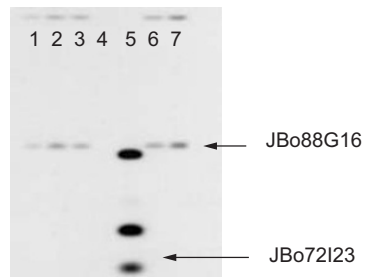

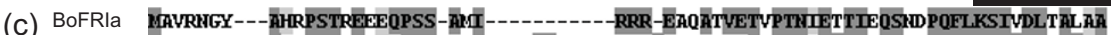
BOFRIb MAFRRDSLIPARDPSTRERK-PSSP-TI----0R-------G------TVPTYTEITIEOSYHHPOFLKSIDDLTAFAT BOFRI
ThFRI EIPARGYS--HHYPSTTEEK-PSSPATTIPRLHORDOSE-RR-GDFPADIRTEPTIKEITSGDSKHPOFMIKSIDDLAKFSA ATFRI --------NSTYPPTVAA-OPTTTA-MPLL-ORHOSEORRR-EL PKTVETESTSTDITIGOSKOPOFLKSIDELAAFSV AIIFRI --------MANYPPTVAA-0-SSTARIPLLHORHOSE-RRRGELPAVVETESTAMEISIGOSKOPOFLKSIDEL AATFSV AlpFRI --------NANYYPPTVAA-0-SSTAAIPLLHORHOSE-RRRGELPAVVETESTAUEISIGOSKOPOFLKSIDELAHFSV

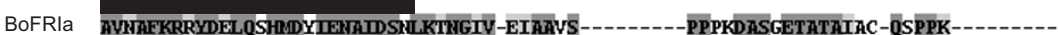
BOFRIb AMDAFKRHYDDLOYHDDYIKNAIGSSLKFKGIIAESPSSRS---0----SPRYDASGETATAVARTOSPPKETSETVPEThFRI AFD AFKRHYDDLOKHMDDIENATESKEKSIYG-Y-DD--SSS--H-----SPEHDASREIATATVC--P PPPEEAETAPEM

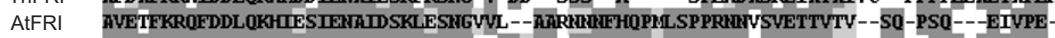

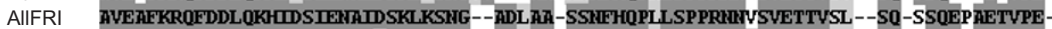

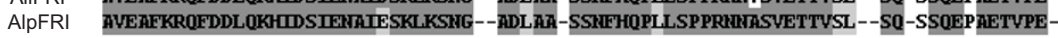

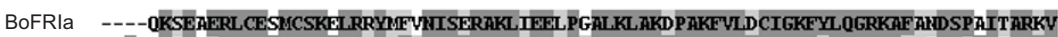
BOFRIb I-S-DKVE--RLCEL MCSKGLRRYYYSMISDRAKLIEEL PAALKL AKEP PAKFVLECIGKFFLOGRKAYASDSHUI PARQV ThFRI ITSYDKAEGORLCESUCSKGLRKYTYAMISERRAKLAEEIPAGLKLLAKEPAKFVLECIGKFYLOGRKAFSHDSHRIPARQV

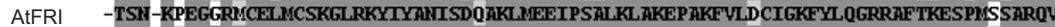
AIIFRI -TSH-KTEGERLCEL.XCSKGLRKYTYAYISDRAKL.MEETPSALKKLAKEPAKFVLECIGKFYLOGRRAFTKESPIYSAROV AlPFRI -TSY-KTEGERLCELMCSKGLRKYTYARISDRAKLMIEEIPSALKLLAKEPAKFVLECIGKFYLOGRRAFTKESPIVSSARQV

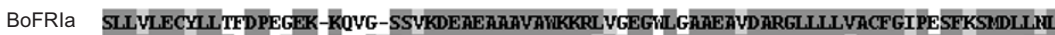

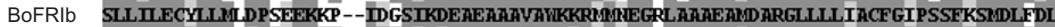

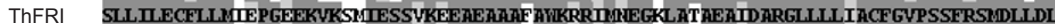
ATFRI SLLIIESFLLMPDRGKGKVK--IESWTKDEAETAAVANRKRLMTEGGL ARAAKKADARGLLLLVVACFGVPSFFRSTDLLDI

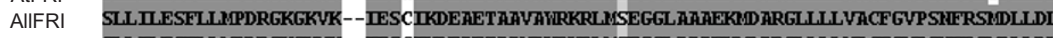

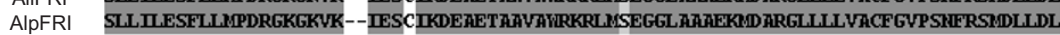

BOFRIa IROSGTAETVGALKRSPFLVPMNSGTVDSSIKRGAHEEALFEYYTFGMEDRFSPSSILTSFLRUSKESFERAKRKAOAPM

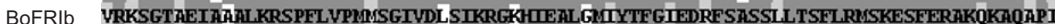
ThFRI IROSGTSEIAGALKRSPFLVPTVSGTVDSCLKRGTHIEZLEIVF TFGUIENI SPSSLLTPFLRKSKESFEL AKRKAHSPT

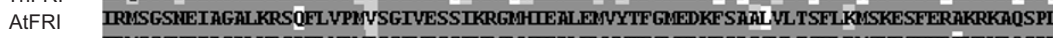

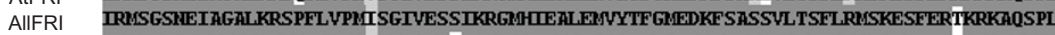

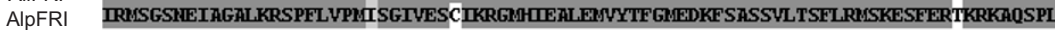

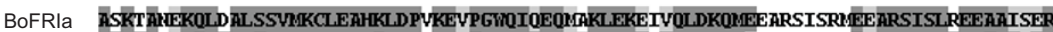

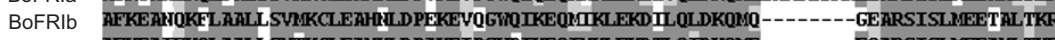
ThFRI AFKEAIEKOLAALLSVTKCLERHKLDPAKEIPGWPIKEOTVKLEKDTLOIDKOME--------EQARSISLAIEEAVLTKR

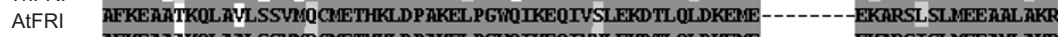

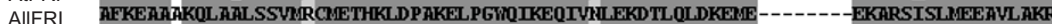

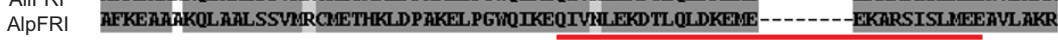

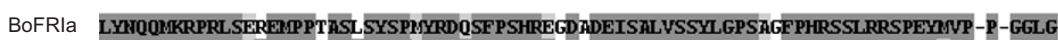
BOFRIb LYYOOMKRPRLSDUIFAPPAASSSYSSTYP ARSFF PSHRD---DEISAL VSSYLEPSPGFPHRSSLRSSPEYLAPPS--GLG

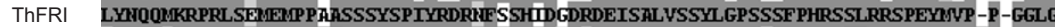

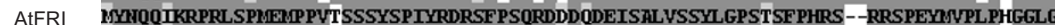
AIIFRI TYYOOMKRPRLSPYIFAIPPVASSSYSSTYLDRSFHSORDEDRDEISALVSSYLGPSSSF PHRSSLLRSPEYTIYPLPPGGLG AlPFRI TYYOOMKRPRLSPMFTIPPVASSSYSSTYLDRSFHSORDEDRDEISALVSSYLGPSSSF PHRSSLRRSPEYTVPLPPGGLG

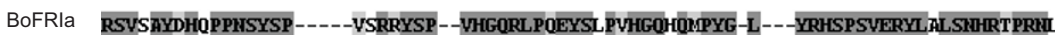
BOFRIb RSVPAYEHLPPTSYLP-----LPRRHSP--VHGORLPGEYSPPTHGOEOISYGRLORVYRHSPSVERYL AL PIHTRSPRUS ThFRI RSUSAYEFLLPSSY-----------SP--VHGORLPREYSPPVHGO0OIPYG-LORVYRHSPSVERLLTLPHHRSPRRS

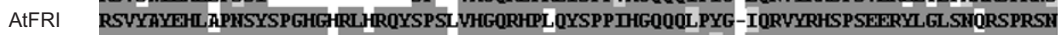

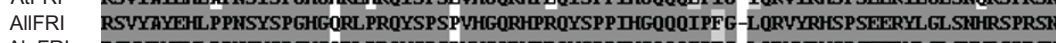
AIPFRI RSVYAYEFLPPIYSYSPGHGORLPROYSPSPVHGORHPRQYSPPDHGOOOIPFG-LORVYRHSPSEERYLGLSWHRSPRSN

BoFRla SODRIGG

BoFRIb -------

ThFRI SQDHIGGM

AtFRI SS--LDPK

AllFRI SS--LDPK

Figure 1 Cloning BoFRIa and BoFRIb. (a) Southern analysis of A12 BACs identified by colony hybridisation and probed with AtFRI. Lanes 1, 4, 5, 8, 11, 12 and 13 contain clones that show homology to FRIGIDA. BACs in lanes 2, 3, 6, 7, and 10 do not cross hybridise (b) HindllI digest of six BACs probed with conserved region from exons 2 and 3 of BoFRla. Lane 5 contains JBo72I23 from which BoFRla was sequenced. Lane 7 contains JBo88G16. Lanes 1, 2, 3 and 6 contain four further BACs showing the same hybridization pattern as JBo88G16. Note the intensity of the hybrization is indicative of the sequence divergence between BoFRla and BoFRlb (See 1c) (c) Comparison of the protein sequences of BoFRla and BoFRlb with other members of the FRI sub-family. From top to bottom they are Brassica oleracea BoFRla, Brassica oleracea BoFRlb, Thelliungiella halophila ThFRl, Arabidopsis thaliana AtFRI Arabidopsis lyrata ssp lyrata AlIFRI and Arabidopsis lyrata ssp petraea AlpFRI. The N-terminal domain containing the conserved region of 37 amino acids (indicated by solid bar) that defines copies of FRIGIDA from other members of the FRI superfamily [17]. The coiled-coil domains are indicated by the red lines. 
between BoFRIa, BoFRIb and AtFRI in the central and Cterminal regions (Figure 1c). Transgenic analysis of the functional domains of AtFRI in A. thaliana where the $\mathrm{N}$ or $\mathrm{C}$ terminus was deleted revealed that the $\mathrm{N}$-terminal region was less important for function [19], perhaps explaining the high degree of divergence observed.

\section{The BoFRI genes map to regions that are non-syntenic} with A. thaliana FRI

A genomic fragment including exon 2, intron 2 and exon 3 of BoFRIa (and showing a high level of conservation in BoFRIb and AtFRI) was hybridized to mapping filters from two $B$. oleracea mapping populations: Chinese kale $\times$ calabrese (var. alboglabra x var. italica; A12DHdxGDDH33, [36]; Figure 2a) and cauliflower $\times$ Brussels sprout (var. botrytis x var. gemmifera; $\mathrm{N} \times \mathrm{G}$ [37]). RFLPs for one of the two BoFRI loci segregated in the A12DHdxGDDH33 mapping population that allowed this locus to be mapped to $39.5 \mathrm{cM}$ on linkage group $\mathrm{C} 3$ of the $B$. oleracea genome. The locus mapping to C3 was identified as BoFRIa by fluorescence in situ hybridization (FISH) with BAC JBo72I23, from which BoFRIa was originally sequenced (Figure 2b). JBo88G16 was located on the short arm of chromosome C9 by FISH (Figure 2c, d). Therefore, the second locus, BoFRIb, was on linkage group C9. Two further BACs showing the same restriction pattern as JBo88G16 (Figure 1b) hybridized to the same location on C9 (data not shown). These results confirm that the $B$. oleracea genome contains two orthologues.

Comparative analysis of the Brassica and A. thaliana genomes has shown that the chromosomal regions of $\mathrm{C} 3$ and $C 9$ to which the two BoFRI loci have been mapped are syntenic to a region of $A$. thaliana chromosome 5 and not to the top of $A$. thaliana chromosome 4, where AtFRI (At4g00650) is located [23]. This region of chromosome 5 includes a number of genes known to be involved in the control of flowering including $F L C, F Y$ and CONSTANS (CO). Several QTL studies have found loci for flowering time variation mapping to this genomic region in a number of Brassica populations including B. oleracea [38-41], B. rapa [42-46]; B. nigra $[47,48]$ and $B$. napus $[29,49]$. The mapping we have undertaken reveals the proximity of BoFRI not only to BoFLC, but also $B o F Y$ and $B o C O$; other flowering time genes that have been mapped previously. The sequences of BoFRIa and $B o F R I b$ further allow us to identify which of the four orthologues of AtFRI recently identified in B. napus [22] are the two $C$ genome copies. The four copies of $F R I$ were designated BnaA.FRI.a, and BnaX.FRIb-d. Comparison of the amino acid sequences of these proteins with BoFRIa and BoFRIb suggest that BnaX.FRI.d is the orthologue of BoFRIa and the $C$ genome homoeologue of BnaA.FRI.a. This conclusion is further supported by the (a)

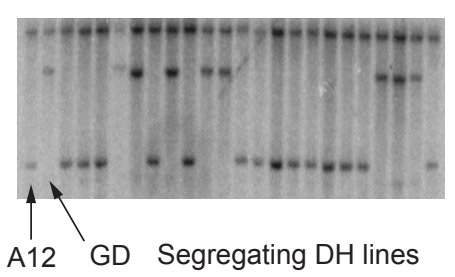

(b)

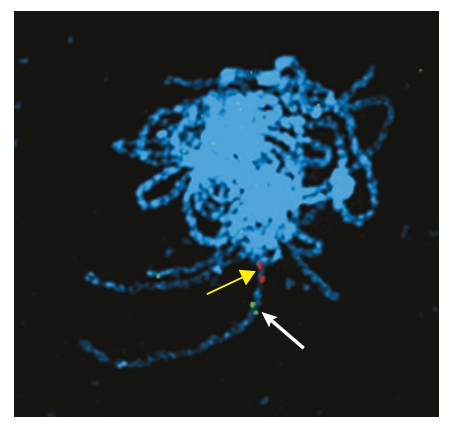

(c)

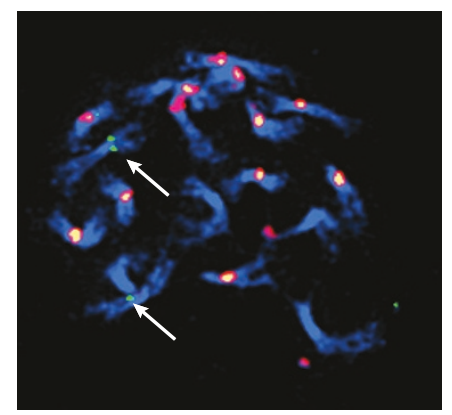

(d)

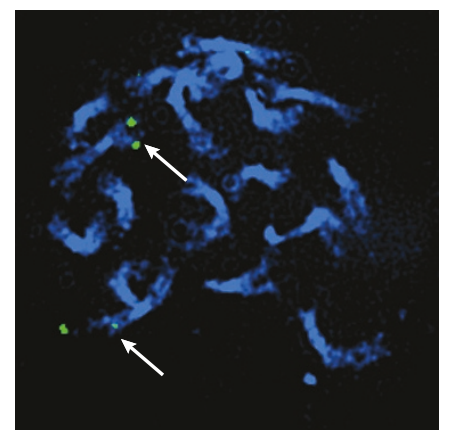

Figure 2 Mapping BoFRla and BoFRIb. (a) A12DHdxGDDH33 mapping population probed with conserved region from exons 2 and 3 of BoFRIa. Two loci are identified; one monomorphic (upper band) and a second segregating with the two parental alleles (lower two bands). (b) Meiotic pachytene spread with JBo72123 (BoFRla, green, white arrow) hybridizing to C3 between the telomere and JBo62M08 (red, yellow arrow). (c) and (d) JBo88G16 (BoFRIb) hybridizes to the short arm of C9: (c) mitotic metaphase with JBo88G16, (green, arrows), BoB061G14 and 45S rDNA (red), (d) reprobe of (c) with JBo32J18 (green, arrows), a marker for C9.

fact that BnaA.FRI.a was mapped to a region of A3 homoeologous to the region of $\mathrm{C} 3$ where we have mapped BoFRIa. Comparison of the amino acid sequence of BnaX.FRI.c shows it to be identical to that of BoFRIb. BnaX.FRI.c appears most similar to BnaX.FRI.b and is 
therefore likely to be the A genome homoeologue of BoFRIb in B. napus.

A recombination event specific to the $A$. thaliana lineage has relocated the FRIGIDA gene to the top of chromosome 4

In A. thaliana, the AtFRI locus is located at the top of chromosome 4. However, it has previously been reported that the orthologue of FRI in A. lyrata maps to linkage group 8 [50,51]. This linkage group is orthologous to the lower arm of $A$. thaliana chromosome 5 $[50,52,53]$. Interestingly, an annotated gene model in this region of A. thaliana chromosome 5 (At5g51090) shows a high degree of homology to AtFRI, containing parts of intron 1 and exon 3 but lacking other parts of the coding region, thus it may be a pseudogene [50]. Genevestigator data suggest At5g51090 is expressed at very low levels, supporting this hypothesis [54]. Downstream, in the opposite orientation, is At5g51100, encoding an iron superoxide dismutase and the BoFRIa BAC clone contains 3' sequence showing homology to exons 3-9 of this A. thaliana chromosome 5 gene (Figure 3a).

Synteny has been studied extensively in the Brassicaceae genomes due to its potential for gene identification

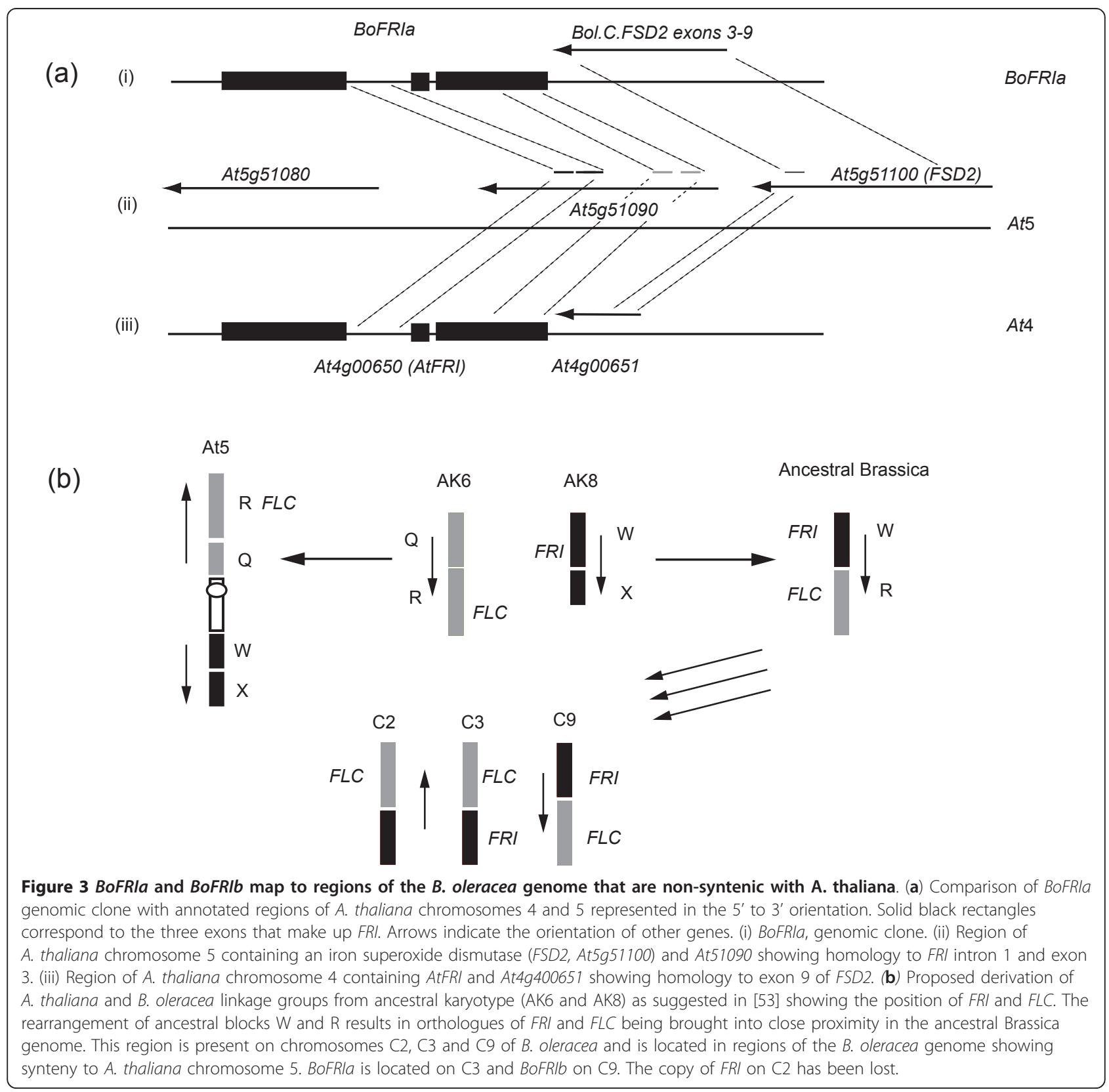


and marker development. Arabidopsis and Brassica are thought to have diverged about 43 Mya with a triplication of an ancestral genome (similar to that of Arabidopsis) occurring approximately 23 Mya and giving rise to modern day diploid Brassica genomes [55]. A. thaliana and $A$. lyrata are thought to have diverged around 13 Mya, with a reduction in chromosome number, from the ancestral karyotype of $\mathrm{n}=8$ (as represented in $A$. lyrata) to the derived state in A. thaliana of $\mathrm{n}=5$ $[24,55,56]$. The ancestral karyotype of the Brassicaceae is proposed to be eight chromosomes composed of 24 conserved chromosomal blocks [57]. These blocks can be rearranged to model the genome structure of $A$. thaliana, A. lyrata and the modern day diploid Brassicas [24]. Thus the genomic composition of the nine chromosomes (C1-C9) of B. oleracea and ten chromosomes (A1-A10) of B. rapa can be related to both the ancestral karyotype and the $A$. thaliana genome.

The ancestral genomic blocks QR and WX from chromosomes 6 and 8 respectively of the ancestral karyotype, and today represented by A. lyrata [24], have been recombined in the ancestral Brassica genome prior to triplication, leading to the block WR being represented three times in the B. rapa genome on A2, A3 and A10 $[25,26]$. The paralogous regions of $B$. oleracea are on $C 2$, $\mathrm{C} 3$ and $\mathrm{C} 9$ (Figure $3 \mathrm{~b})$. This rearrangement brings orthologues of FLC (block R) and FRI (block W) together on these chromosomes. Thus in A. lyrata and B. oleracea, FRI maps quite closely to VIN3 (also in block W and required for vernalization [58], as well as its major target FLC (block R; Figure 3b). BoFRIa mapping to $\mathrm{C} 3$ and $B o F R I b$ to $C 9$ thus represent two of the three syntenic regions. The third paralogue of FRI appears to have been lost from C2 during B. oleracea evolution; such gene loss is not uncommon [59]. This is in contrast to the current location of FRI at top of chromosome 4 in A. thaliana that shows homology to block $O$ from chromosome 6 of the ancestral karyotype.

The data we present here suggest that the chromosomal rearrangements that occurred during the evolution of the ancestral Brassicaceae genome into A. thaliana included a recombination/rearrangement event that relocated a genomic region containing AtFRI to a position near the distal end of the short arm of chromosome 4 , close to the nucleolar organiser region, leaving a nonfunctional remnant in the genomic position on chromosome 5 that is syntenic with FRI in the other Brassicaceae (A. lyrata, B. oleracea; [25,52]).

\section{Two common alleles exist for BoFRla in diverse genotypes of $B$. oleracea}

The original sequences of BoFRIa and BoFRIb were obtained from A12DHd, one of the parents of the mapping population used in $[38,39]$. These studies mapped
QTL for flowering time on C3 in the region where we have mapped BoFRIa. We therefore sequenced $650 \mathrm{bp}$ from exon 1 of BoFRIa from the other parent of this population, GDDH33 (data not shown). The GDDH33 sequence showed two amino acid substitutions (A118V and Q125E) compared to A12DHd. Thus the parents of this population are carrying different alleles of BoFRIa and it is possible that variation at BoFRIa is contributing to variation in flowering time in this population. Single amino acid substitutions have also been identified in alleles of BnaA.FRI.a sequenced from the parents of the Tapidor $\times$ Ningyou7 (TN) mapping population from B. napus and mapped to a region underlying a QTL for flowering time variation [22].

We sequenced BoFRIa and BoFRIb for two additional genotypes of $B$. oleracea italica. The A12DHd reference sequence is derived from a BAC clone of a Chinese kale, B. oleracea alboglabra, which flowers after 8 weeks [38] and can be considered a rapid-cycling type, not requiring vernalization. We therefore selected two additional genotypes of broccoli (Brassica oleracea italica); E1, which has a facultative vernalization response, flowering earlier following a period of cold, but which matures in October/November (Autumn) of the year of planting and E8 which has an obligate vernalization requirement and matures in April/May (Spring) of the following year. BoFRIb is highly conserved between the three genotypes with only 5 amino acid substitutions (D6G, K20Q, Q372K and R532W in E1 and N105T in E8). The sequencing of BoFRIa in these genotypes identified a polymorphic region in exon 1 that included two deletions of seven and three amino acids in E8 relative to E1, either side of the conserved block of 37 amino acids that defines the FRI proteins, (Figure 1c). Thirteen non-synonymous and 12 synonymous substitutions differentiate the A12DHd and E1 BoFRIa alleles from the E8 allele. We therefore designated the E1 and E8 BoFRIa alleles as BoFRIa-1 and BoFRIa-4 respectively [GenBank JN191393, JN191392].

We focused our subsequent analysis on BoFRIa as this showed most polymorphism and extended our analysis to include 55 genotypes from the cultivated $B$. oleracea Diversity Foundation Set developed at the University of Warwick (BolDFS, King et al. http://www.brassica.info/ resource/plants/diversity_sets.php; [60] Table 1). A 650 bp region of BoFRIa covering the exon 1 polymorphic region containing the two deletions was sequenced (Table 1, GenBank JN191394-191448). We identified six BoFRIa alleles within this subset of 55 genotypes from the BolDFS. These can be divided into two groups; BoFRIa 1-3 and BoFRIa 4-6 where alleles in the second group include the seven amino acid and three amino acid deletions. The BoFRIa- 1 and BoFRIa-4 alleles were the most common within the 55 genotypes studied. In 


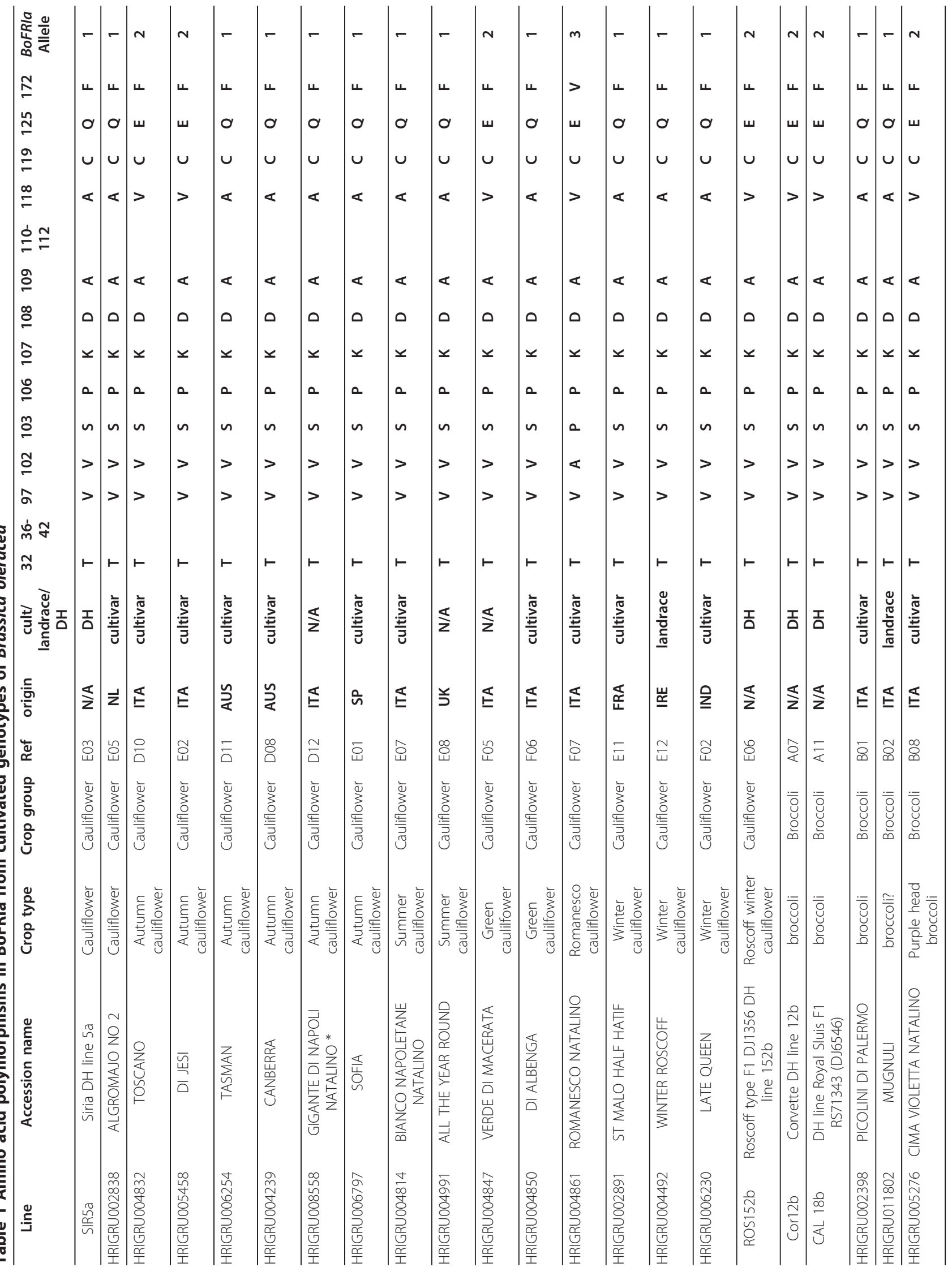




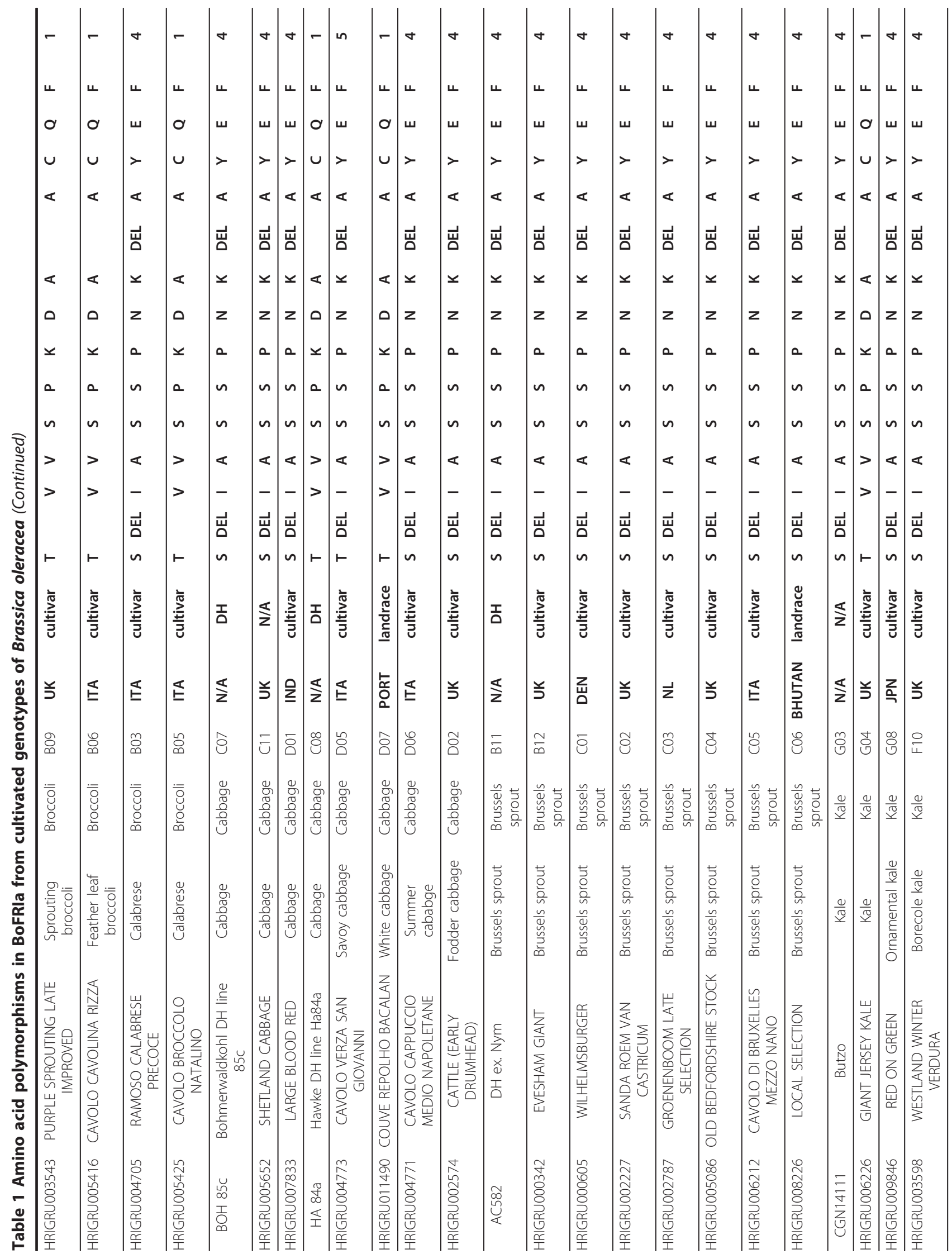




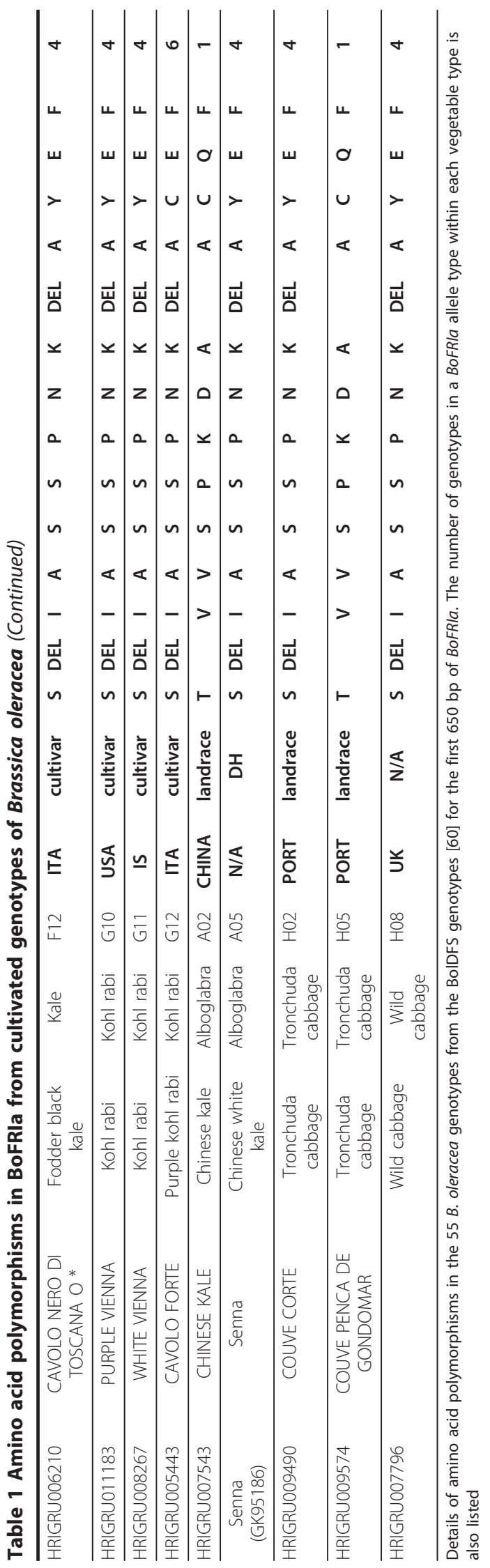


addition the two deletions identified in BoFRIa-4 always co-occurred and were found at high frequency together with a small number of non-synonymous nucleotide polymorphisms. The two deletions, which had been found in the late-flowering broccoli, were over-represented in B. oleracea vegetable types such as Brussels sprouts and kohl rabi with a winter annual or biennial habit, usually grown for consumption of their vegetative rather than floral forms (Table 1, Figure 4). Interestingly BnaX.FRI.d from the B. napus winter variety Express [22], which we have identified here as the $C$ genome homologue of BoFRIa in B. napus has both of the deletions identified in the BoFRI 4-6 class of alleles that are overrepresented in brassica vegetable types with a winter annual or biennial habit. On closer examination BnaX. FRI.d was found to have the same amino acid sequence as BoFRIa-5 and is also present in the European winter type and Chinese semi-winter type parental lines of the TN mapping population [22].

\section{Functional analysis of BoFRla alleles in A. thaliana}

To ascertain if the two most common BoFRIa alleles conferred any functional differences we undertook transformation experiments. The coding and 3'UTR sequences from the BoFRIa-1 and BoFRIa-4 alleles were used to replace the AtFRI coding and 3' UTR sequences in an $A$. thaliana genomic clone. By retaining common regulatory sequences in the 5 ' region from the AtFRI gene we hoped to normalise expression and thus focus on the structural differences between the two Brassica proteins. These constructs were transformed into the rapid-cycling $A$. thaliana accession Columbia (Col-0). Col-0 carries a loss-of-function mutation within AtFRI, but has a functional FLC so these experiments would determine if BoFRIa could complement the fri mutation in Col-0, and induce late flowering. Both BoFRIa alleles complemented the loss-of-function mutation with $>100$ primary (T1) transformed plants containing each of the BoFRIa alleles flowering very late compared to Col-0 plants and surprisingly also later than Col-0 transformed with a functional AtFRI (Figure 5).

To investigate the functionality of BoFRIa-1 and BoFRIa-4 alleles under different environmental conditions five transformants carrying each allele were analysed in the next (T2) generation. Flowering time was analysed as days-to-flower and total leaf number in plants that had no vernalization, or had experienced two or four weeks vernalization, at either $5^{\circ} \mathrm{C}$ or $10^{\circ} \mathrm{C}$ (Figure 6). In all treatments, except two weeks at $10^{\circ} \mathrm{C}\left(2 \mathrm{~W} 10^{\circ} \mathrm{C}\right)$, plants with either BoFRIa allele flowered as late as those carrying AtFRI. At $2 \mathrm{~W} 10^{\circ} \mathrm{C}$ plants carrying either of the BoFRIa alleles flowered later than AtFRI. Figure 6 also shows that plants undergoing a vernalization treatment at $10^{\circ} \mathrm{C}$ compared to $5^{\circ} \mathrm{C}$ continue to grow and initiate leaves at a faster rate.
Thus, when considering total leaf number as a measure of flowering time it appears that only $4 \mathrm{~W} 5^{\circ} \mathrm{C}$ was an effective vernalization treatment (Figure 6).

Expression of the coding sequences of the two BoFRIa alleles under the AtFRI 5' regulatory sequences showed that both alleles can produce functionally equivalent proteins that may, under some environmental conditions, be even stronger with respect to flowering time effects than the endogenous A. thaliana protein (Figure 6). In contrast, two $A$. lyrata FRI alleles conferred a quantitative difference in flowering time by both association and transgenic studies [16]. The maintenance of both $A$. lyrata alleles at intermediate frequencies in natural populations suggests they are differentially selected in different environments. If the BoFRIa alleles do underlie flowering time QTL then there must be expression differences between the two genes to account for the difference in flowering time. Both these genes could be expressed in a very different pattern to AtFRI as the rearrangement that moved it to chromosome 4 resulted in completely different 5 ' sequences less than $1 \mathrm{~kb}$ upstream of the transcription start site and places it in a very different chromatin context since it is now 200-300 kb downstream of the heterochromatic nucleolar organizer region NOR4 [61].

\section{Conclusions}

Knowledge of $B$. oleracea FRI gene number, functionality and map position now puts us in a strong position to undertake an extensive investigation into the contribution of allelic variation at FRI to flowering, vernalization and life history behaviours. Differences in life history between $A$. lyrata and $A$. thaliana such as outcrossing versus selfing and a perennial compared to annual habit may result in a requirement for some level of FRI functionality in $A$. lyrata that is optional in A. thaliana [16]. B. oleracea, like A. lyr$a t a$, is a largely outcrossing species and some wild $B$. olera$c e a$, thought to be the progenitor of the modern crop plants, have been reported to keep flowering for up to 20 years [62]. Our analysis of BoFRIa suggests that only a small number of functional BoFRIa alleles are captured within the cultivated $B$. oleracea germplasm. To date we have found no evidence for loss-of-function mutations that are frequent in AtFRI. Further analysis of the 5' and 3' regulatory regions of $B o F R I$ is now underway. The proximity of BoFRI to BoFLC, BoFY and BoCO opens up new questions of how this may influence flowering behaviour. It will be particularly important to be in a position to select specific alleles in breeding programmes to allow us to enhance robustness against increasing climate variability.

\section{Methods \\ Cloning BoFRI genes}

The JBo BAC library was hybridised with the AtFRI genomic clone, originally from the accession Stockholm 


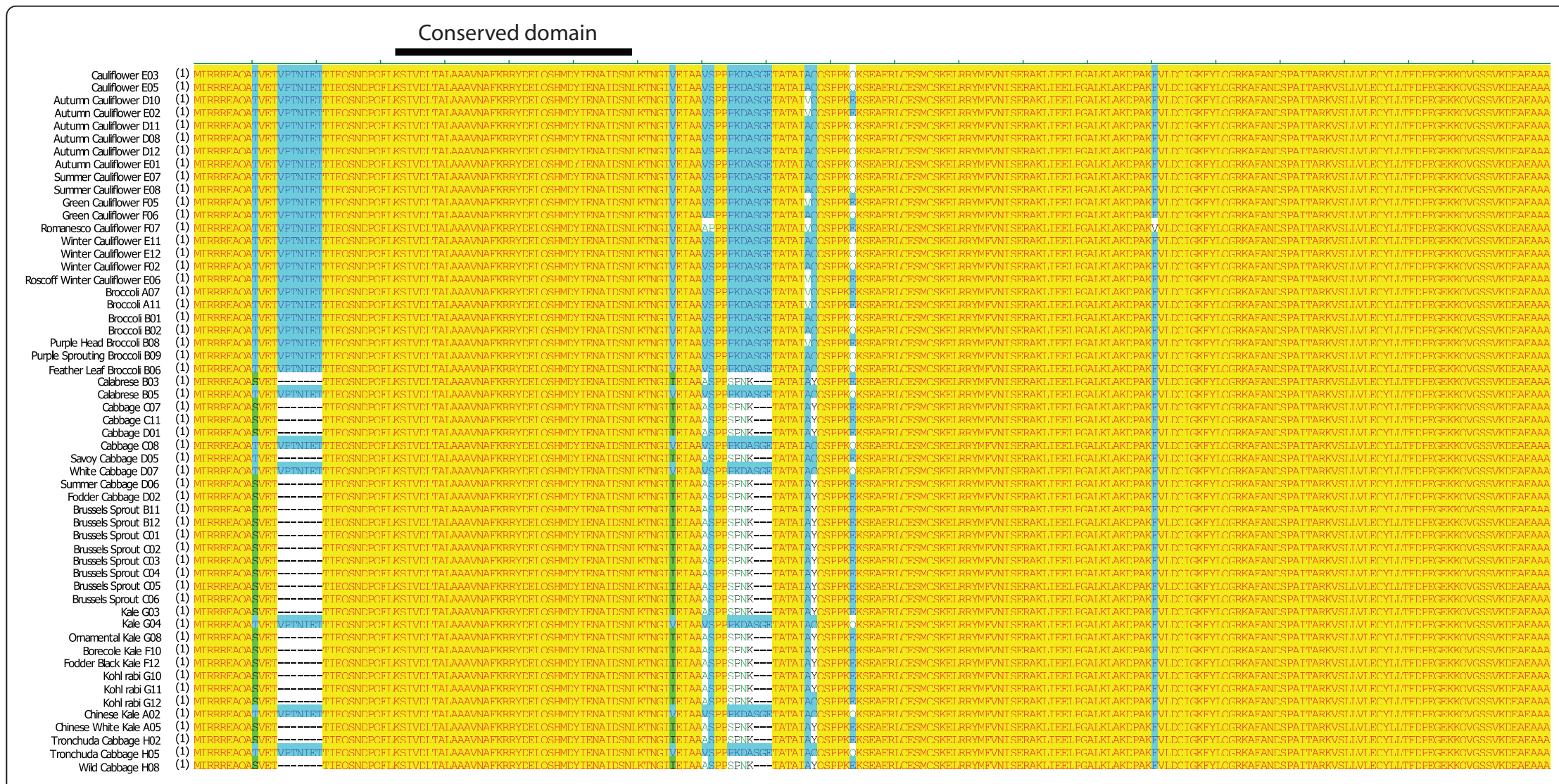

Figure 4 Comparison of first 160 amino acids of BoFRla from 55 BolDFS genotypes. Protein comparison of BoFRla from cultivated genotypes of B. oleracea listed by crop type. The plate co-ordinates refer to those listed in Table 1. The conserved region of 37 amino acids that defines FRI from other members of the FRI superfamily is delineated by the horizontal black bar. 


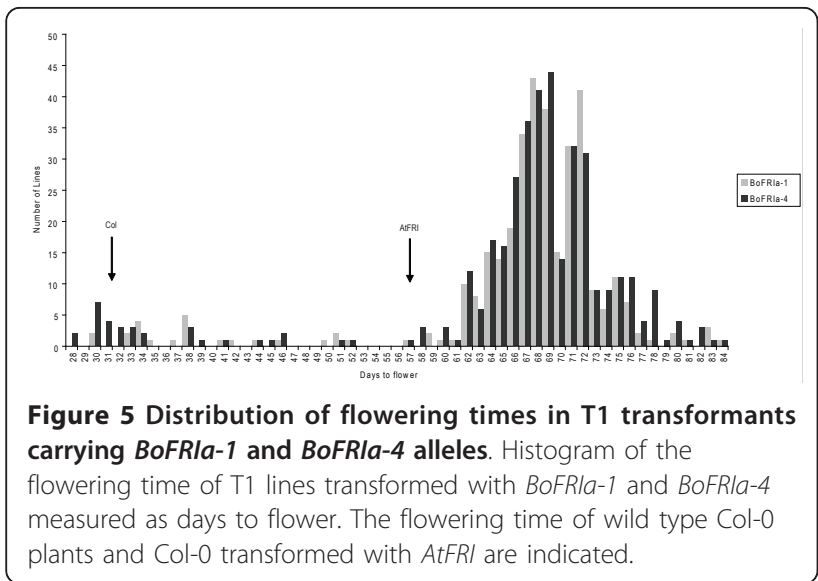

[8] and seven BACs identified, six having identical restriction patterns and one different. Purified genomic DNA was prepared (Qiagen Maxi Prep Kit) from two of these BACs (72I23 and 88G16) and used to generate shotgun libraries (TOPOr Shotgun Kit) of 1-2 kb fragments, in the $\mathrm{pCR}^{\mathrm{R}} 4 \mathrm{Blunt}^{-\mathrm{TOPO}^{\mathrm{R}}}$ vector, giving 6-fold coverage. Colonies from these libraries were gridded onto nylon membrane (HyBond-N+) and hybridised to three probes generated from AtFRI (the 5' region, exon 1 , and the 3' end of exon 3 and 3' UTR). BAC subclones were identified with each of these probes. Sequence analysis confirmed that the two BACs carried different Brassica paralogues.

\section{Mapping BoFRI loci in B. oleracea mapping populations Genetic mapping}

Mapping filters of the A12DHdxGDDH33 mapping population were produced and hybridized with a conserved BoFRI probe as described in [36,63]. A 900 bp conserved region from exons 2 and 3 from BoFRIb was amplified from A12DHd genomic DNA with primers J2NG_F1 (5' AAGTATCAAGCGTGGAAAGCA 3') and J2NG_R1 (5' GTTACGAGGAGACCTGTGATT 3') and used to probe both the A12DHdxGDDH33 and NxG mapping filters (supplied by Graham Teakle, WHRI). Linkage analysis to map the BoFRIa locus was performed using Joinmap 3.0 [64] with the mapping data provided at BrassicaDB http:// brassica.bbsrc.ac.uk/BrassicaDB/.

\section{Fluorescence in situ hybridisation (FISH)}

FISH was performed on chromosome spreads from the A12DHd genotype of B. oleracea using methods described in [65]. The chromosomes are now named according to their corresponding linkage group. JBo72I23 was applied to meiotic pachytene spreads together with JBo62M08, a $\mathrm{BAC}$ which is associated with the RFLP marker pN22 on $\mathrm{C} 3$ at $42 \mathrm{cM}$ and previously assigned to chromosome C3 by FISH. JBo88G16 (BoFRIb) was applied to mitotic metaphase spreads together with BAC BoB061G14, which
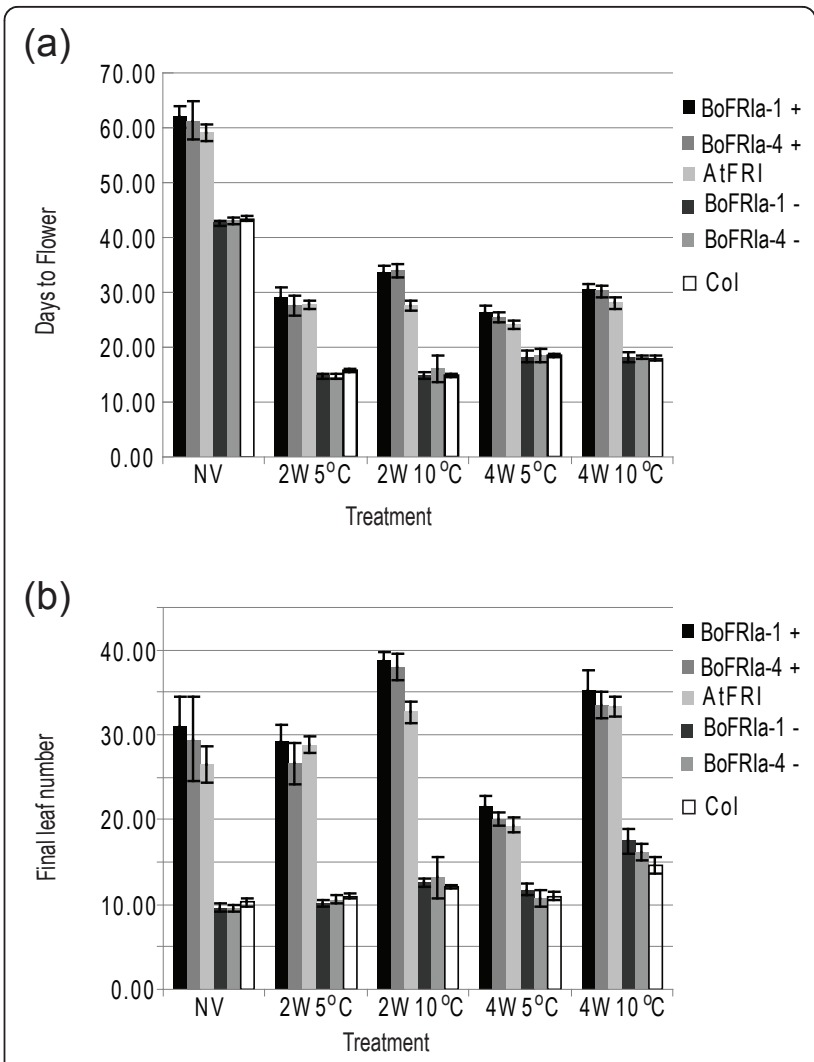

Figure 6 Functional analysis of the two most common BoFRla alleles. Average flowering time of $\mathrm{T} 2$ families transformed with the two major BoFRla alleles BoFRIa-1 and BoFRla-4 and compared to Col-0 transformed with the AtFRI allele and Col-0 wild type. (a) Flowering time measured as days-to-flower. The error bars show 95\% confidence intervals. (b) Flowering time measured as final leaf number. The error bars show $95 \%$ confidence intervals. Segregating progeny with and without the transgene are indicated by + and respectively.

hybridizes to pericentromeric heterochromatin of six pairs of chromosomes, and a $45 \mathrm{~S}$ rDNA probe from clone pTa71 [66], EMBLX07841. The chromosome pair to which JBo88G16 hybridized lacked signals from the other probes and had morphology suggestive of C9. Therefore, slides were reprobed with JBo32J18, a BAC associated with BoFLC1 which has been mapped to a region between pN47E4NM (87 cM) and pN3E1 (103 cM) on C9 [31,67] and confirmed to be on C9 by FISH (unpublished). Two further BACs showing the same restriction pattern as JBo88G16 were applied separately with JBo88G16 to pachytene spreads.

\section{Sequencing BoFRla in BolDFS}

The $B$. oleracea diversity foundation set (BolDFS) is a core collection of lines that represent the genetic variation across the morphologically diverse crops of this species http://www.brassica.info/resource/plants/diversity_sets. php. DNA was isolated using the DNeasy 96 Plant Kit 
(Qiagen) and amplified using the GenomiPhi whole genome amplification kit (GE healthcare). A 650 bp fragment of BoFRIa was amplified from genomiphied DNA of 55 genotypes of the BolDFS by PCR with primers YWFRI_F (5'CGCACATCGTCCATCAACAAG 3') and FRIJ1_R2 (5'ATCCTTCACCCACCAGCCT 3') using AMPLITAQ GOLD TAQ DNA Polymerase (Life Technologies Ltd (Invitrogen Division)). Sequence analysis was conducted using AlignX in Vector NTI (Invitrogen).

\section{Functional analysis of BoFRla alleles}

Plasmid pFRIg (in pBluescript-KS+, Stratagene) was mutagenised to introduce a BamHI site immediately 5' of the ATG (plasmid pFRIg-B). Digestion of pFRIg-B with BamHI plus ClaI allowed removal of the AtFRI coding sequences, leaving the 5' region of AtFRI. A 4.3 $\mathrm{kb}$ fragment containing BoFRIa was isolated from genomic DNA of lines E1 and E8 by PCR with primers BoFRI1_ Bam_ATG (5'CTTCCGCGGATCCCATGGCCGTCCGTAAC3') and BoFRI1_R2_ClaI (5'CAGAGATCGATC TCGAGAAAGGTAGCTGTTT 3'), using Pfulltra II Fusion HS DNA Polymerase (Agilent Technologies) and sequenced. PCR products were digested with BamHI plus ClaI and the purified fragments ligated into BamHI plus ClaI-digested pFRIg-B to give final constructs containing the 5'UTR of AtFRI with the coding and 3' UTR sequences of BoFRIa-1 (in BoFRIa-1) or BoFRIa-4 (in BoFRIa-4). pFRIg-B was used as the A. thaliana FRI control. The final constructs were ligated into binary vector pSLJ755I6 (a gift from Prof. Jonathan Jones, http://www.tsl.ac.uk/research/ jonathan-jones/plasmids.htm), on an EcoRI plus XhoI fragment (pFRIg-B) or EcoRI plus ClaI fragments (from BoFRIa-1 and BoFRIa-4). The constructs were transferred into Agrobacterium by triparental mating [68] and transformed into A. thaliana accession Col-0 by a floral dipping method (modified from [69]). T1 transformants were isolated by selection for Basta ${ }^{\mathrm{TM}}$ resistance. T2 seed were collected and flowering time determined by days-to-flower excluding the period of vernalization treatment and final leaf number at flowering.

\section{Plant growth}

T2 A. thaliana seeds were sown on 'Arabidopsis mix' (Scotts ${ }^{\circledR}$ Levington F2 $8.75 \mathrm{l}$ bags, $100 \mathrm{l}$ of grit, $200 \mathrm{~g}$ of Imidasect ${ }^{\circledR} 5$ gr. $)$ in plastic pots $(7 \mathrm{~cm} \times 7 \mathrm{~cm})$ and stratified in a vernalization chamber at $5^{\circ} \mathrm{C}$ with an $8 \mathrm{~h}$ photoperiod and constant humidity for 3 days. Pots were moved to a naturally lit long day glasshouse for 7 days in May 2010 to allow germination and pre-growth. Seedlings not receiving a vernalization treatment remained in the glasshouse; seedlings to be vernalization treated were transferred back to a vernalization room or controlled environment cabinet (Snijder Economic Deluxe) for a treatment of either two or four weeks at $5^{\circ} \mathrm{C}$ or $10^{\circ} \mathrm{C}$. After vernalization, 20 plants per line were transplanted into trays with 40 cells of $2 \mathrm{~cm} \times 2 \mathrm{~cm}$ and returned to the glasshouse. Trays were moved regularly to random positions to prevent any positional effects on plant growth. Flowering time was recorded as either total leaf number (rosette leaves plus cauline leaves at flowering) or bolting time; bolting time was scored as the number of days-toflowering determined when the inflorescence stem was $3 \mathrm{~cm}$ tall.

\section{Abbreviations}

QTL: Quantitative trait loci; BAC: Bacterial artificial chromosome; ORF: open reading frame; FISH: fluorescence in situ hybridization.

\section{Acknowledgements}

We thank David Laurie, Lars Østergaard and Martin Trick for critical reading of the manuscript, Theresa Townsend for help with initial BAC identification, David Turner (JIC genome lab), for BAC library construction and initial sequencing of BoFRla and BoFRIb, John Walshaw for advice on coiled-coil analysis and Sue Kennedy at Elsoms Seeds Ltd for seeds of E1 and E8. We also thank Andreas Mueller for early access to the B. napus FRI sequences following electronic publication. This work was funded by Defra grant HH3708SFV, Defra feasibility Horticulture LINK grant HL0186, and BBSRC Strategic Grant to The John Innes Centre. The B. oleracea Diversity Foundation Set was produced at the University of Warwick with funding from Defra projects IF0157 and HH3723XS.

\section{Author details}

${ }^{1}$ Department of Cell and Developmental Biology, John Innes Centre, Norwich Research Park, Norwich NR4 7UH, UK. ${ }^{2}$ School of Biosciences, University of Birmingham, Birmingham B15 2TT, UK. ${ }^{3}$ School of Life Sciences, University of Warwick, Wellesbourne CV35 9EF, UK.

\section{Authors' contributions}

$J I$ and CD conceived and designed the experiments, supervised the work and wrote the paper. CL, YZ and JI analyzed the BoFRla alleles. ES and Jl analyzed the BolDFS and GT contributed DNA from the BolDFS. EH performed the FISH experiments. All authors approved and read the final manuscript.

Received: 2 November 2011 Accepted: 14 February 2012 Published: 14 February 2012

\section{References}

1. Simpson GG, Dean C: Flowering - Arabidopsis, the Rosetta stone of flowering time? Science 2002, 296:285-289.

2. Baurle I, Dean C: The timing of developmental transitions in plants. Cell 2006, 125:655-664.

3. Amasino R: Seasonal and developmental timing of flowering. Plant J 2010, 61:1001-1013.

4. Hayama R, Yokol S, Tamaki S, Yano M, Shimamoto K: Adaptation of photoperiodic control pathways produced short-day flowering in rice. Nature 2003, 422:719-722.

5. Franks SJ, Sim S, Weis AE: Rapid evolution of flowering time by an annual plant in response to a climate fluctuation. Proc Natl Acad Sci (USA) 2007, 104:1278-1282.

6. Wilczek AM, Roe JL, Knapp MC, Cooper MD, Lopez-Gallego C, Martin LJ, Muir CD, Sim S, Walker A, Anderson J, Egan JF, Moyers BT, Petipas R, Giakountis A, Charbit E, Coupland G, Welch SM, Schmitt J: Effects of Genetic Perturbation on Seasonal Life History Plasticity. Science 2009, 323:930-934.

7. Sandring S, Riihimaki MA, Savolainen O, Agren J: Selection on flowering time and floral display in an alpine and lowland population of Arabidopsis lyrata. J Evolution Biol 2007, 20:558-567.

8. Johanson U, West J, Lister C, Michaels S, Amasino R, Dean C: Molecular analysis of FRIGIDA, a major determinant of natural variation in Arabidopsis flowering time. Science 2000, 290:344-347. 
9. Gazzani S, Gendall AR, Lister C, Dean C: Analysis of the molecular basis of flowering time variation in Arabidopsis accessions. Plant Physiol 2003, 132:1107-1114.

10. Lempe J, Balasubramanian S, Sureshkumar S, Singh A, Schmid M, Weigel D: Diversity of flowering responses in wild Arabidopsis thaliana strains. PLoS Genetics 2005, 1(1):e6.

11. Shindo C, Aranzana MJ, Lister C, Baxter C, Nicholls C, Nordborg M, Dean C: Role of FRIGIDA and FLOWERING LOCUS C in determining variation in flowering time of Arabidopsis. Plant Physiol 2005, 138:1163-1173.

12. Sheldon CC, Rouse DT, Finnegan EJ, Peacock WJ, Dennis ES: The molecular basis of vernalization: The central role of FLOWERING LOCUS C (FLC). ProC Natl Acad Sci (USA) 2000, 97:3753-3758.

13. Michaels SD, Amasino RM: Loss of FLOWERING LOCUS C activity eliminates the late-flowering phenotype of FRIGIDA and autonomous pathway mutations but not responsiveness to vernalization. Plant Cell 2001, 13:935-941.

14. Le Corre V, Roux F, Reboud X: DNA polymorphism at the FRIGIDA gene in Arabidopsis thaliana: extensive nonsynonymous variation is consistent with local selection for flowering time. Mol Biol Evol 2002, 19:1261-1271.

15. Colosimo PF, Hosemann KE, Balabhadra S, Villarreal G Jr, Dickson M, Grimwood J, Schmutz J, Myres RM, Schluter D, Kingsley DM: Widespread parallel evolution in sticklebacks by repeated fixation of Ectodysplasin alleles. Science 2005, 307:1928-1933.

16. Kuittinen $H$, Niittyvuopio $A$, Rinne $P$, Savolainen $O$ : Natural variation in Arabidopsis lyrata vernalization requirement conferred by a FRIGIDA indel polymorphism. Mol Biol Evol 2008, 25:319-329.

17. Slotte T, Huang H, Lascoux M, Ceplitis A: Polyploid speciation did not confer instant reproductive isolation in Capsella (Brassicaceae). Mol Biol Evol 2008, 25:1472-1481.

18. Fang $Q$, Liu J, Xu Z, Song R: Cloning and characterization of a flowering time gene from Thellungiella halophila. Acta Bioch Bioph Sin 2008, 40:747-753.

19. Risk JM, Laurie RE, Macknight RC, Day CL: FRIGIDA and related proteins have a conserved central domain and family specific $\mathrm{N}$ - and $\mathrm{C}$ - terminal regions that are functionally important. Plant Mol Biol 2010, 73:493-505.

20. Keller SR, Levsen N, Ingvarsson PK, Olson MS, Tiffin P: Local selection across a latitudinal gradient shapes nucleotide diversity in Balsam Poplar, Populus balsamifera L. Genetics 2011, 188:941-952.

21. Goff SA, Ricke D, Lan TH, Presting G, Wang R, Dunn M, Glazebrook J, Sessions A, Oeller P, Varma H, Hadley D, Hutchison D, Martin C, Katagiri F, Lange BM, Moughamer T, Xia Y, Budworth P, Zhong J, Miguel T, Paszkowski U, Zhang S, Colbert M, Sun WL, Chen L, Cooper B, Park S, Wood TC, Mao L, Quail P, et al: A draft sequence of the rice genome (Oryza sativa L. ssp japonica). Science 2002, 296:92-100.

22. Wang N, Qian W, Suppanz I, Wei L, Mao B, Long Y, Meng J, Müller AE, Jung $C$ : Flowering time variation in oilseed rape (Brassica napus $L$.) is associated with allelic variation in the FRIGIDA homologue BnaA.FRI.a. J Exp Bot 2011, 62:5641-5658

23. Parkin IAP, Gulden SM, Sharpe AG, Lukens L, Trick M, Osborn TC, Lydiate DJ: Segmental structure of the Brassica napus genome based on comparative analysis with Arabidopsis thaliana. Genetics 2005, 171:765-781.

24. Schranz ME, Lysak MA, Mitchell-Olds T: The ABC's of comparative genomics in the Brassicaceae: building blocks of crucifer genomes. Trends Plant Sci 2006, 11:535-542.

25. Trick M, Kwon SJ, Choi SR, Fraser F, Soumpourou E, Drou N, Wang Z, Lee SY, Yang TJ, Mun JH: Complexity of genome evolution by segmental rearrangement in Brassica rapa revealed by sequence-level analysis. BMC Genomics 2009, 10:539.

26. Mun JH, Kwon SJ, Kim JA, Jin M, Kim JS, Lim MH, Lee SI, Hong JK, Park TH, Lee SC, Kim BJ, Seo MS, Baek S, Lee MJ, Shin JY, Hahn JH, Hwang YJ, Lim KB, Park JY, Lee J, Yang TJ, Yu HJ, Choi IY, Choi BS, Choi SR, Ramchairy N, Lim YP, Fraser F, Drou N, Soumpourou E, et al: Sequence and structure of Brassica rapa chromosome A3. Genome Biol 2010, 11:R94.

27. Suwabe $K$, Tsukazaki $H$, Iketani $H$, Hatakeyama K, Kondo M, Fujimura M, Nunome T, Fukuoka H, Hirai M, Matsumoto S: Simple sequence repeatbased comparative genomics between Brassica rapa and Arabidopsis thaliana: the genetic origin of clubroot resistance. Genetics 2006, 173:309-319.
28. Gao M, Li G, Yang B, Qiu D, Farnham M, Quiros C: High-density Brassica oleracea linkage map: identification of useful new linkages. Theor App/ Genet 2007, 115:277-287.

29. Long Y, Shi J, Qiu D, Li R, Zhang C, Wang J, Hou J, Zhao J, Shi L, Park BS: Flowering time quantitative trait loci analysis of oilseed Brassica in multiple environments and genome wide alignment with Arabidopsis. Genetics 2007, 177:2433.

30. Smooker AM, Wells R, Morgan C, Beaudoin F, Cho K, Fraser F, Bancroft I: The identification and mapping of candidate genes and QTL involved in the fatty acid desaturation pathway in Brassica napus. Theor App Genet 2011, 122:1075-1090.

31. Razi H, Howell EC, Newbury HJ, Kearsey MJ: Does sequence polymorphism of FLC paralogues underlie flowering time QTL in Brassica oleracea? Theor App Genet 2008, 116:179-192.

32. O'Neill CM, Bancroft I: Comparative physical mapping of segments of the genome of Brassica oleracea var. alboglabra that are homoeologous to sequenced regions of chromosomes 4 and 5 of Arabidopsis thaliana. Plant J 2000, 23:233-243.

33. Østergaard L, King GK: Standardized gene nomenclature for the Brassica genus. Plant Methods 2008, 4:10-13.

34. Lupas A, Van Dyke M, Stock J: Predicting Coiled Coils from Protein Sequences. Science 1991, 252:1162-1164.

35. Michaels SD, Bezerra IC, Amasino RM: FRIGIDA-related genes are required for the winter-annual habit in Arabidopsis. Proc Natl Acad Sci USA 2004, 101:3281-3285.

36. Bohuon EJR, Keith DJ, Parkin IAP, Sharpe AG, Lydiate DJ: Alignment of the conserved C genomes of Brassica oleracea and Brassica napus. Theor Appl Genet 1996, 93:833-839.

37. Sebastian RL, Kearsey MJ, King GJ: Identification of quantitative trait loci controlling developmental characteristics of Brassica oleracea L. Theor Appl Genet 2002, 104:601-609.

38. Bohuon EJR, Ramsay LD, Craft JA, Arthur AE, Marshall DF, Lydiate DJ, Kearsey MJ: The association of flowering time quantitative trait loci with duplicated regions and candidate loci in Brassica oleracea. Genetics 1998, 150:393-401.

39. Rae AM, Howell EC, Kearsey MJ: More QTL for flowering time revealed by substitution lines in Brassica oleracea. Heredity 1999, 83:586-596.

40. Okazaki K, Sakamoto K, Kikuchi R, Saito A, Togashi E, Kuginuki Y, Matsumoto S, Hirai M: Mapping and characterization of $F L C$ homologs and QTL analysis of flowering time in Brassica oleracea. Theor Appl Genet 2007, 114:595-608.

41. Uptmoor R, Schrag T, Stützel H, Esch E: Crop model based QTL analysis across environments and QTL based estimation of time to floral induction and flowering in Brassica oleracea. Mol Breeding 2008, 21:205-216.

42. Schranz ME, Quijada P, Sung SB, Lukens L, Amasino R, Osborn TC: Characterization and effects of the replicated flowering time gene $F L C$ in Brassica rapa. Genetics 2002, 162:1457-1468.

43. Nishioka M, Tamura K, Hayashi M, Fujimori Y, Ohkawa Y, Kuginuki Y, Harada K: Mapping of QTLs for bolting time in Brassica rapa (syn. campestris) under different environmental conditions. Breeding Sci 2005, 55:127-133.

44. Lou P, Zhao JJ, Kim JS, Shen SX, Del Carpio DP, Song XF, Jin MN, Vreugdenhil D, Wang XW, Koornneef M, Bonnema G: Quantitative trait loci for flowering time and morphological traits in multiple populations of Brassica rapa. J Exp Bot 2007, 58:4005-4016.

45. Yang X, Yu YJ, Zhang FL, Zou ZR, Zhao XY, Zhang DS, Xu JB: Linkage Map Construction and Quantitative Trait Loci Analysis for Bolting Based on a Double Haploid Population of Brassica rapa. J Integrative Plant Biol 2007, 49:664-671.

46. Zhao J, Kulkarni V, Liu N, Del Carpio DP, Bucher J, Bonnema G: BrFLC2 (FLOWERING LOCUS C) as a candidate gene for a vernalization response QTL in Brassica rapa. J Exp Bot 2010, 61:1817-1825.

47. Axelsson T, Shavorskaya O, Lagercrantz U: Multiple flowering time QTLs within several Brassica species could be the result of duplicated copies of one ancestral gene. Genome 2001, 44:856-864.

48. Osterberg MK, Shavorskaya O, Lascoux M, Lagercrantz U: Naturally occurring indel variation in the Brassica nigra COL1 gene is associated with variation in flowering time. Genetics 2002, 161:299-306. 
49. Pires JC, Zhao JW, Schranz ME, Leon EJ, Quijada PA, Lukens LN, Osborn TC: Flowering time divergence and genomic rearrangements in resynthesized Brassica polyploids (Brassicaceae). Biol J Linn Soc 2004 82:675-688.

50. Kuittinen $H$, de Haan AA, Vogl C, Oikarinen S, Leppala J, Koch M, MitchellOlds T, Langley $\mathrm{CH}$, Savolainen O: Comparing the linkage maps of the close relatives Arabidopsis lyrata and A. thaliana. Genetics 2004, 168:1575-1584.

51. Beaulieu J, Belzile F, Jean M: Linkage maps for Arabidopsis lyrata subsp. lyrata and Arabidopsis lyrata subsp. petraea combining anonymous and Arabidopsis thaliana-derived markers. Genome 2007, 50:142-150.

52. Yogeeswaran K, Frary A, York TL, Amenta A, Lesser AH, Nasrallah JB, Tanksley SD, Nasrallah ME: Comparative genome analyses of Arabidopsis spp.: inferring chromosomal rearrangement events in the evolutionary history of $A$. thaliana. Genome Res 2005, 15:505-515.

53. Hu TT, Pattyn P, Bakker EG, Cao J, Cheng JF, Clark RM, Fahlgren N, Fawcett JA, Grimwood J, Gundlach H, Haberer G, Hollister JD, Ossowski S, Ottilar RP, Salamov AA, Schneeberger K, Spannagl M, Wang X, Yang L, Nasrallah ME, Bergelson J, Carrington JC, Gaut BS, Schmutz J, Mayer KFX, Van De Peer Y, Grigoriev IV, Nordborg M, Weigel D, Guo YL: The Arabidopsis lyrata genome sequence and the basis of rapid genome size change. Nat Genet 2011, 43:476-481.

54. Hruz T, Laule O, Szabo G, Wessendorp F, Bleuler S, Oertle L, Wdimayer P, Gruissem W, Zimmermann P: Genevestigator V3: a reference expression database for the meta-analysis of transcriptomes. Advances in Bioinformatics 2008, 420747.q.

55. Beilstein MA, Nagalingum NS, Clements MD, Manchester SR, Mathews S: Dated molecular phylogenies indicate a Miocene origin for Arabidopsis thaliana. Proc Natl Acad Sci (USA) 2010, 107:18724-18728.

56. Koch MA, Matschinger M: Evolution and genetic differentiation among relatives of Arabidopsis thaliana. Proc Natl Acad Sci (USA) 2007, 104:6272-6277.

57. Lysak MA, Berr A, Pecinka A, Schmidt R, McBreen K, Schubert I: Mechanisms of chromsome number reduction in Arabidopsis thaliana and related Brassicaceae species. Proc Natl Acad Sci (USA) 2006, 103:5224-5229.

58. Sung SB, Amasino RM: Vernalization in Arabidopsis thaliana is mediated by the PHD finger protein VIN3. Nature 2004, 427:159-164.

59. Town CD, Cheung F, Maiti R, Crabtree J, Haas BJ, Wortman JR, Hine EE, Althoff R, Arbogast TS, Tallon L, Vigouroux M, Trick M, Bancroft I: Comparative genomics of Brassica oleracea and Arabidopsis thaliana reveal gene loss, fragmentation, and dispersal after polyploidy. Plant Cell 2006, 18:1348-1359.

60. Allender CJ, Allainguillaume J, Lynn J, King GJ: Simple sequence repeats reveal uneven distribution of genetic diversity in chloroplast genomes of Brassica oleracea L. and ( $\mathrm{n}=9$ ) wild relatives. Theor App/ Genet 2007 , 114:609-618.

61. Schmidt R, West J, Cnops G, Love K, Balestrazzi A, Dean C: Detailed description of four YAC contigs representing $17 \mathrm{Mb}$ of chromosome 4 of Arabidopsis thaliana ecotype Columbia. Plant J 1996, 9:755-765.

62. Raybould AF, Mogg RJ, Clarke RT, Gliddon CJ, Gray AJ: Variation and population structure at microsatellite and isozyme loci in wild cabbage (Brassica oleracea L.) in Dorset (UK). Genet Resour Crop Ev 1999, 46:351-360.

63. Sharpe AG, Parkin IAP, Keith DJ, Lydiate DJ: Frequent non-reciprocal translocations in the amphidiploid genome of oilseed rape (Brassica napus). Genome 1995, 38:1112-1121.

64. van Ooijen JW, Voorrips RE: JoinMap version 3.0: Software for the calculation of genetic linkage map. Wageningen: Plant Research International; 2001

65. Howell EC, Barker GC, Jones GH, Kearsey MJ, King GJ, Kop EP, Ryder CD, Teakle GR, Vicente JG, Armstrong SA: Integration of the cytogenetic and genetic linkage maps of Brassica oleracea. Genetics 2002, 161:1225-1234.

66. Gerlach WL, Bedbrook JR: Cloning and characterisation of ribosomal genes from wheat and barley. Nucleic Acids Res 1979, 7:1869-1885.

67. Salathia NS: Regulation of Biological clocks i Brassica olerace and Arabidopsis thalian. University of Warwick: PhD Dissertation; 2003.

68. Figurski DH, Helinski DR: Replication of an origin-containing derivative of plasmid RK2 dependent on a plasmid function provided in trans. Proc Natl Acad Sci (USA) 1979, 76:1648-1652.
69. Bechtold N, Ellis J, Pelleteir G: In planta Agrobacterium mediated gene transfer by infltration of adult Arabidopsis thaliana plants. C R Acad Sci Paris Life Sci 1993, 316:1194-1199.

doi:10.1186/1471-2229-12-21

Cite this article as: Irwin et al.: Functional alleles of the flowering time regulator FRIGIDA in the Brassica oleracea genome. BMC Plant Biology 2012 12:21.

\section{Submit your next manuscript to BioMed Central and take full advantage of:}

- Convenient online submission

- Thorough peer review

- No space constraints or color figure charges

- Immediate publication on acceptance

- Inclusion in PubMed, CAS, Scopus and Google Scholar

- Research which is freely available for redistribution

Submit your manuscript at www.biomedcentral.com/submit
Ciomed Central 